\title{
Methionine transport in the malaria parasite Plasmodium falciparum
}

\author{
Simon A. Cobbold ${ }^{\mathrm{a}}$, Rowena E. Martin ${ }^{\mathrm{a}, \mathrm{b}}$, Kiaran Kirk ${ }^{\mathrm{a}, *}$ \\ ${ }^{a}$ Research School of Biology, The Australian National University, Canberra, ACT 0200, Australia \\ ${ }^{\mathrm{b}}$ School of Botany, The University of Melbourne, Parkville, VIC 3010, Australia
}

\section{A R T I C L E I N F O}

\section{Article history:}

Received 26 June 2010

Received in revised form 31 August 2010

Accepted 1 September 2010

\section{Keywords:}

Malaria

Membrane transport

Amino acid

Transporter

\begin{abstract}
A B S T R A C T
The intraerythrocytic malaria parasite, Plasmodium falciparum, derives amino acids from the digestion of host cell haemoglobin. However, it also takes up amino acids from the extracellular medium. Isoleucine is absent from adult human haemoglobin and an exogenous source of isoleucine is essential for parasite growth. An extracellular source of methionine is also important for the normal growth of at least some parasite strains. In this study we have characterised the uptake of methionine by $P$. falciparum-infected human erythrocytes, and by parasites functionally isolated from their host cells by saponin-permeabilization of the erythrocyte membrane. Infected erythrocytes take up methionine much faster than uninfected erythrocytes, with the increase attributable to the flux of this amino acid via the New Permeability Pathways induced by the parasite in the erythrocyte membrane. Having entered the infected cell, methionine is taken up by the intracellular parasite via a saturable, temperature-dependent process that is independent of ATP, $\mathrm{Na}^{+}$and $\mathrm{H}^{+}$. Substrate competition studies, and comparison of the transport of methionine with that of isoleucine and leucine, yielded results consistent with the hypothesis that the parasite has at its surface one or more transporters which mediate the flux into and out of the parasite of a broad range of neutral amino acids. These transporters function most efficiently when exchanging one neutral amino acid for another, thus providing a mechanism whereby the parasite is able to import important exogenous amino acids in exchange for surplus neutral amino acids liberated from the digestion of host cell haemoglobin.
\end{abstract}

(c) 2010 Australian Society for Parasitology Inc. Published by Elsevier Ltd. All rights reserved.

\section{Introduction}

As the malaria parasite, Plasmodium falciparum, grows within the erythrocytes of its human host it ingests and degrades up to $75 \%$ of host cell haemoglobin (Loria et al., 1999). Less than $20 \%$ of the amino acids derived from haemoglobin degradation are utilised by the parasite for protein synthesis (Krugliak et al., 2002). The parasite exports the majority of the amino acids liberated from haemoglobin to the extracellular medium (Krugliak et al., 2002), whilst maintaining a high intracellular concentration of free amino acids, estimated to be of the order of $20-30 \mathrm{mM}$ (Teng et al., 2009).

Not all of the parasite's amino acid requirements are met by the breakdown of haemoglobin. Adult haemoglobin contains no isoleucine and parasite growth is reliant on a supply of this amino acid in the extracellular solution (Siddiqui and Schnell, 1972; Divo et al., 1985). A second amino acid, present at low levels in human adult haemoglobin, for which an external source is required for normal growth by some, but not all, $P$. falciparum strains (Siddiqui and Schnell, 1972; Liu et al., 2006) is methionine. Furthermore, it

\footnotetext{
* Corresponding author. Tel.: +612 61253841; fax: +61261250758.

E-mail address: kiaran.kirk@anu.edu.au (K. Kirk).
}

has been shown in metabolic labelling experiments that the parasite is able to take up and incorporate into protein, all 20 of the naturally-occurring $\alpha$-amino acids (Sherman, 1977; Divo et al., 1985; Elford et al., 1985; Ginsburg et al., 1985; Kirk et al., 1994). The available data are therefore consistent with the presence in the membranes of both the host erythrocyte and the intracellular parasite, of amino acid transport pathways, capable of mediating both the influx and efflux of the full range of amino acids.

Normal human erythrocytes take up isoleucine and methionine via the saturable L-system (Winter and Christensen, 1964; Rosenberg, 1982; Barker and Ellory, 1990; Tunnicliff, 1994). In human erythrocytes infected with the mature $P$. falciparum trophozoite there is a dramatic increase in the rate of amino acid influx, attributable to New Permeability Pathways (NPPs) induced by the parasite in the host cell membrane (Martin and Kirk, 2007). These are broad-specificity pathways, permeable to a wide range of low molecular weight organic and inorganic solutes, and inhibited by a variety of anion transport inhibitors including furosemide (Huber et al., 2005; Staines et al., 2007; Merckx et al., 2009; Hill and Desai, 2010). On entering the infected cell, isoleucine is taken up by the intracellular parasite via a high-capacity saturable transport process that has been characterised in some detail (Martin and Kirk, 2007), although not yet identified at a molecular level. 
By contrast with isoleucine, the transport of methionine in the $P$. falciparum-infected erythrocyte has not been investigated in any detail. Early studies of erythrocytes infected with Plasmodium knowlesi (McCormick, 1970), Plasmodium lophurae (Sherman et al., 1971) and P. falciparum (Kirk et al., 1994) all indicated increased methionine uptake in infected compared with uninfected cells. In the present study we have characterised the transport of methionine into $P$. falciparum-infected erythrocytes, and into and out of the intracellular parasite. The transport of methionine into infected cells was shown to be via a combination of the endogenous L-system and the parasite-induced NPPs. Measurements on isolated parasites revealed the presence in the parasite plasma membrane of one or more saturable transporters able to transport a diverse range of neutral amino acids.

\section{Materials and methods}

\subsection{Cells and solutions}

Human erythrocytes infected with $P$. falciparum (strain FAF6) were maintained in continuous suspension (Allen and Kirk, 2009), in synchronous cultures (Lambros and Vanderberg, 1979) in Group O, Rh + erythrocytes. Experiments were carried out using trophozoite-infected cells (approximately 30-35 h post-invasion).

Prior to experimentation, $P$. falciparum-infected erythrocytes were concentrated to between $85 \%$ and $98 \%$ parasitemia using a VarioMACS separation unit (Miltenyi Biotec, North Ryde, NSW, Australia) as described elsewhere (Teng et al., 2009). Infected erythrocytes were eluted from the VarioMACS column and resuspended in RPMI media (bicarbonate free) supplemented with $25 \mathrm{mM}$ HEPES, $10 \mathrm{mM}$ glucose, $200 \mu \mathrm{M}$ hypoxanthine, $0.6 \% \mathrm{w} / \mathrm{v}$ Albumax II and $24 \mathrm{mg} / \mathrm{L}$ gentamicin sulphate, then incubated at $37{ }^{\circ} \mathrm{C}$ for $15 \mathrm{~min}$ to allow the cells to recover before proceeding with experimentation.

A number of different solutions were used in this study: solution A (130 mM NaCl, $25 \mathrm{mM}$ HEPES, $5 \mathrm{mM} \mathrm{KCl,} 20 \mathrm{mM}$ glucose, $1 \mathrm{mM} \mathrm{MgCl}_{2}$ and supplemented with RPMI 1640 vitamins and glutathione (Invitrogen); $\mathrm{pH} 7.4$ ); solution $\mathrm{B}$ (same as solution A but with no glucose); solution C (130 mM NaCl, $25 \mathrm{mM}$ HEPES, $5 \mathrm{mM}$ $\mathrm{KCl}, 20 \mathrm{mM}$ glucose, $1 \mathrm{mM} \mathrm{MgCl}$ : $\mathrm{pH} 7.1$ ); solution D (135 mM $\mathrm{NaCl}, 25 \mathrm{mM}$ HEPES, $5 \mathrm{mM} \mathrm{KCl}$ and $1 \mathrm{mM} \mathrm{MgCl}_{2}$ : $\mathrm{pH} 7.1$ ); solution $\mathrm{E}\left(\mathrm{Na}^{+}\right.$free; same as solution $\mathrm{D}$ but containing $135 \mathrm{mM}$ choline chloride in place of $\mathrm{NaCl})$; solution $\mathrm{F}$ (125 mM NaCl, $25 \mathrm{mM}$ HEPES,

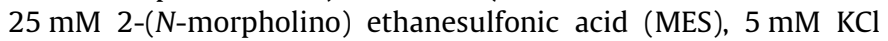
and $1 \mathrm{mM} \mathrm{MgCl}_{2}$; $\left.\mathrm{pH} 5.5 / 6.2 / 7.1 / 7.8\right)$.

\subsection{Uptake measurements in intact erythrocytes}

The influx of methionine into uninfected erythrocytes and intact infected erythrocytes was estimated from the uptake of $\left[{ }^{3} \mathrm{H}\right]$ methionine. All experiments on intact erythrocytes were carried out in the presence of the naturally-occurring amino acids at concentrations approximating those found in adult human plasma (Merck, 1974): alanine $(356 \mu \mathrm{M})$, arginine $(88 \mu \mathrm{M})$, asparigine $(13 \mu \mathrm{M})$, aspartate $(13 \mu \mathrm{M})$, cystine $(37 \mu \mathrm{M})$, glutamate $(57 \mu \mathrm{M})$, glutamine $(476 \mu \mathrm{M})$, glycine $(217 \mu \mathrm{M})$, histidine $(85 \mu \mathrm{M})$, hydroxyproline $(8 \mu \mathrm{M})$, isoleucine $(70 \mu \mathrm{M})$, leucine $(100 \mu \mathrm{M})$, lysine $(163 \mu \mathrm{M})$, methionine $(17 \mu \mathrm{M})$, phenylalanine $(100 \mu \mathrm{M})$, proline $(165 \mu \mathrm{M})$, serine $(128 \mu \mathrm{M})$, threonine $(112 \mu \mathrm{M})$, tryptophan $(50 \mu \mathrm{M})$, tyrosine $(62 \mu \mathrm{M})$ and valine $(190 \mu \mathrm{M})$. Amino acids compete with one another for transporter proteins and the inclusion of the full range of amino acids at concentrations approximating those in blood plasma allows an assessment of the relative contributions of different transport systems to amino acid uptake under in vivo conditions.
Parasitised erythrocytes (85-98\% parasitemia) or uninfected erythrocytes (maintained under culture conditions for $48 \mathrm{~h}$ prior to experimentation) were suspended at a concentration of approximately $5 \times 10^{7}$ cells $/ \mathrm{mL}$ at $37^{\circ} \mathrm{C}$ in solution $\mathrm{A}$ or solution $\mathrm{B}$. An appropriate volume of reaction medium (identical to the solution in which the cells were suspended but supplemented with all of the common amino acids as well as $\left[{ }^{3} \mathrm{H}\right]$ methionine and, where appropriate, transport inhibitors) was dispensed into a microcentrifuge tube and warmed to $37^{\circ} \mathrm{C}$. Influx commenced with the addition of an equal volume of cell suspension, immediately followed by mixing. The final concentration of each amino acid in the extracellular medium fell within the normal plasma range (see above) and the final activity of the $\left[{ }^{3} \mathrm{H}\right]$ methionine was $2 \mu \mathrm{Ci} / \mathrm{mL}$. In those cases in which transport inhibitors were used they were added to the suspension immediately prior to combining the cells with radiolabel. At predetermined intervals (timecourses) or after $20 \mathrm{~s}$ (fixed-time period experiments) aliquots of the suspension $(200 \mu \mathrm{L})$ were transferred to microcentrifuge tubes containing $300 \mu \mathrm{L}$ dibutyl phthalate (density $1.04 \mathrm{~g} / \mathrm{mL}$ ) layered

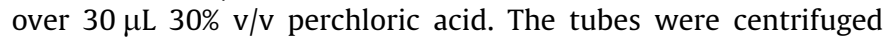
immediately $(12,000 \mathrm{~g} ; 1 \mathrm{~min})$ to sediment the cells through the oil and into the acid, thereby terminating the flux, lysing the cells and precipitating the protein. The solution remaining above the oil was aspirated. The sides of the tube were washed three times to remove residual radioactivity and the remaining oil was then aspirated. Trichloroacetic acid $(1 \mathrm{~mL}, 5 \% \mathrm{w} / \mathrm{v})$ was added to the perchloric acid extract and the sample was then centrifuged $(12,000 \mathrm{~g} ; 8 \mathrm{~min})$. The radioactivity in the supernatant solution (approximately $1 \mathrm{~mL}$; referred to here as 'acid-soluble') was measured using a $\beta$-scintillation counter. In a number of such experiments the acid-insoluble protein pellet at the bottom of the microcentrifuge tube was dissolved and the radioactivity measured as described previously (Martin and Kirk, 2007), in order to assess the extent of incorporation of $\left[{ }^{3} \mathrm{H}\right]$ methionine into the acid-insoluble protein fraction.

Transport/protein synthesis rates measured in suspensions of parasitised erythrocytes (85-98\% parasitemia) were corrected to those for cells at $100 \%$ parasitemia by subtracting the small contribution of the uninfected cells (determined on the basis of measurements on uninfected cells), then dividing by the fractional parasitemia.

\subsection{Influx and efflux measurements in isolated parasites}

The transport of amino acids across the parasite plasma membrane was characterised in parasites functionally isolated from their host erythrocytes by treatment of parasitised erythrocytes with saponin. The saponin forms pores in both the erythrocyte and parasitophorous vacuole membranes, thereby releasing the contents of the host erythrocyte and allowing solutes in the extracellular medium free access to the parasite surface. The parasite plasma membrane remains intact and able to generate and maintain substantial ionic gradients (Saliba and Kirk, 1999; Alleva and Kirk, 2001; Spillman et al., 2008) and a large, inwardly negative membrane potential (Allen and Kirk, 2004). Such parasites, within permeabilised erythrocytes, are henceforth referred to as 'isolated parasites'.

Influx and efflux of methionine, isoleucine and leucine in isolated parasites was measured using $\left[{ }^{3} \mathrm{H}\right]$ methionine, $\left[{ }^{14} \mathrm{C}\right]$ isoleucine and $\left[{ }^{14} \mathrm{C}\right]$ leucine, respectively. Except where specified otherwise, flux measurements were carried out at $4{ }^{\circ} \mathrm{C}$ (to slow the rate of transport) with parasites suspended at a concentration of $0.5-1.0 \times 10^{8}$ cells $/ \mathrm{mL}$ in the presence of the protein synthesis inhibitors cycloheximide $(40 \mu \mathrm{M})$ and anisomycin $(150 \mu \mathrm{M})$ (Martin and Kirk, 2007). The majority of experiments were carried out using ATP-depleted parasites in order to eliminate the 
contribution of ATP-dependent metabolic processes to the measured uptake of radiolabel (see Kirk et al., 2009).

Isolated parasites were prepared by the addition of $0.05 \% \mathrm{w} / \mathrm{v}$ saponin (giving a final concentration of $0.005 \% \mathrm{w} / \mathrm{v}$ for the active agent sapogenin) to parasitised erythrocytes (85-98\% parasitemia) suspended at $37{ }^{\circ} \mathrm{C}$ in RPMI 1640 media. Immediately following the addition of saponin, the cells were centrifuged (3000g; $8 \mathrm{~min}$ ) and the saponin-containing solution removed. The cells were resuspended and centrifuged $(16,000 \mathrm{~g} ; 1 \mathrm{~min})$ three times in solution C, incubated for $10 \mathrm{~min}$ in solution C (to allow recovery) then, in most cases and unless specified otherwise, washed and resuspended (three times) in (glucose-free) solution D and incubated for a further $10 \mathrm{~min}$ at $37^{\circ} \mathrm{C}$ in solution D. The $10 \mathrm{~min}$ incubation in solution D served to reduce parasite ATP to a negligible level (Saliba and Kirk, 1999). In those few experiments carried out on ATP-replete isolated parasites the second 10 min incubation was in (glucose-containing) solution C. Neither solution C nor solution $\mathrm{D}$ contained amino acids and the prolonged incubation of the isolated parasites in these two media ( $>20 \mathrm{~min}$ in total) resulted in a depletion of intracellular neutral amino acids (see Fig. 5 below), such that (unless specified otherwise) amino acid influx measurements were carried out under nominally 'zero-trans' condition.

For influx experiments the uptake of radiolabel was initiated by combining an aliquot of the suspension of isolated parasites with an equivalent volume of solution containing the radiolabelled substrate. The final activity of radiolabel was $2.0-2.5 \mu \mathrm{Ci} / \mathrm{mL}$. Uptake was terminated at predetermined times by centrifuging the isolated parasites through an oil layer comprising a blend of dibutyl phthalate and dioctyl phthalate $(5: 4 ; 1.015 \mathrm{~g} / \mathrm{mL})$, into $30 \% \mathrm{v} / \mathrm{v}$ perchloric acid. In the majority of experiments the cell suspension and the solution containing the radiolabelled substrate were combined in a single tube and at predetermined times aliquots of the radiolabelled suspension were layered on top of the oil mixture and then centrifuged. In one experiment requiring rapid sampling of time points (giving rise to the inset in Fig. 2A), an aliquot $(200 \mu \mathrm{L})$ of the solution containing the radiolabelled methionine was layered directly on top of the oil in a microcentrifuge tube positioned in the centrifuge rotor. At predetermined times the cell suspension $(200 \mu \mathrm{L})$ was added to the radiolabelled solution on top of the oil. Activation of the centrifuge (as little as 1-2 s after combining the cell suspension and radiolabel) terminated the flux.

Efflux experiments were performed using isolated parasites suspended in solution D and pre-loaded with $\left[{ }^{3} \mathrm{H}\right]$ methionine, $\left[{ }^{14} \mathrm{C}\right]$ isoleucine or $\left[{ }^{14} \mathrm{C}\right]$ leucine in the presence of protein synthesis inhibitors. In each case, the radiolabel (at an activity of 2, 6 and $6 \mu \mathrm{Ci} / \mathrm{mL}$, respectively) was allowed to equilibrate between the intra- and extracellular solutions (15 min incubation), the parasites were washed by centrifugation $(12,000 \mathrm{~g} ; 1 \mathrm{~min})$ and then resuspended in fresh solution. At predetermined time points samples of the suspension were taken and the cells separated from the extracellular solution by centrifugation through an oil layer (into $30 \% \mathrm{v} / \mathrm{v}$ perchloric acid).

For both the influx and efflux experiments the perchloric acid extracts were processed for $\beta$-scintillation counting as described for the intact erythrocyte samples.

In one set of experiments (giving rise to Fig. 7) the ability of extracellular (unlabelled) amino acids to stimulate the efflux from the parasite of (pre-loaded) radiolabelled amino acids was investigated. The experimental procedure was adapted from Martin and Kirk (2007) with some modifications. Isolated ATP-depleted parasites were suspended in solution $\mathrm{D}$ in the presence of protein synthesis inhibitors. $\left[{ }^{3} \mathrm{H}\right]$ methionine, $\left[{ }^{14} \mathrm{C}\right]$ isoleucine or $\left[{ }^{14} \mathrm{C}\right]$ leucine were added (at an activity of $1.5,3.0$ and $3.0 \mu \mathrm{Ci} / \mathrm{mL}$, respectively) and allowed to equilibrate then, at time-zero, unlabelled methionine, isoleucine, leucine, alanine or aspartate (each at a concentration of $1 \mathrm{mM}$ ) was added to the suspension. At predetermined time intervals the parasites were centrifuged through an oil layer and the pellets processed for $\beta$-scintillation counting.

\subsection{Estimation of extracellular space, centrifugation times and intracellular concentrations}

In influx experiments the volume of extracellular solution (and hence the amount of radiolabel) trapped between the cells as they were centrifuged through the oil layer was estimated by taking replicate samples as quickly as possible after combining the cells and radiolabel and centrifuging these through an oil layer as described above. In experiments with intact infected (and uninfected) erythrocytes the extent of extracellular trapping of radiolabel was estimated in cells to which furosemide had been added immediately before combining cells and radiolabel in order to minimise the uptake of radiolabelled solute via the parasite-induced NPPs during the few seconds required to take and process the samples. The final furosemide concentration was $200 \mu \mathrm{M}$. In such experiments (with intact erythrocytes) the extracellular volume typically comprised $5-10 \%$ of the total pellet volume. In experiments with isolated parasites the extracellular trapping of radiolabelled amino acid was estimated in samples to which had been added a $10 \mathrm{mM}$ concentration of the corresponding unlabelled amino acid in order to slow the uptake of radiolabel. In such experiments (with isolated parasites) the extracellular volume typically comprised approximately $45 \%$ of the total pellet volume.

In those experiments in which initial transport rates were estimated on the basis of time points acquired over $\leqslant 30 \mathrm{~s}$, account was taken of the time-lag between starting the microcentrifuge and the actual cessation of uptake of radiolabel. The time-lag was estimated by acquiring time-courses for the uptake of methionine (with multiple points taken over the initial $30 \mathrm{~s}$ ), fitting a straight line to the uptake data and extrapolating the line to yield an estimate of the time at which there was zero uptake of radiolabel. Using this approach it was determined that in experiments on isolated parasites conducted with modern 'brushless motor' microcentrifuges the lag-time was of the order of 8-10 s whereas in experiments conducted with older 'brush motor' microcentrifuges the lag-time was of the order of 4-5 s. These values were confirmed in a second set of experiments in which isolated parasite suspensions layered onto oil were centrifuged for different lengths of time $(0-10 \mathrm{~s})$ and the extent to which the cells were pelleted through the oil was determined visually.

Intracellular concentrations of radiolabelled solute (and hence the 'distribution ratio'; i.e. the concentration of radiolabel inside the cell, relative to that in the extracellular solution) were calculated from the amounts of radiolabel taken up by the cells, in conjunction with previous estimates of the water volume of trophozoite-stage $P$. falciparum-infected erythrocytes (75 fL) and saponin-isolated parasites ( $28 \mathrm{fL}$ ) (Saliba et al., 1998).

\section{Results}

\subsection{Human erythrocytes infected with P. falciparum have increased permeability to methionine}

Fig. 1A shows time-courses for the uptake of methionine into uninfected and $P$. falciparum-infected human erythrocytes, measured at $37{ }^{\circ} \mathrm{C}$ in the presence of approximately physiological concentrations of the naturally-occurring amino acids, including $17 \mu \mathrm{M}$ methionine. The initial rate of influx of methionine into uninfected cells under these conditions was $73 \pm 10 \mathrm{nmol} /\left(10^{12}\right.$ cells min) ( $n=3 ; \pm$ standard error (SE); Fig. 1A, closed squares). In $P$. falciparum-infected erythrocytes the rate of uptake was increased dramatically; the initial influx rate was $1.10 \pm 0.21 \mu \mathrm{mol} /$ 

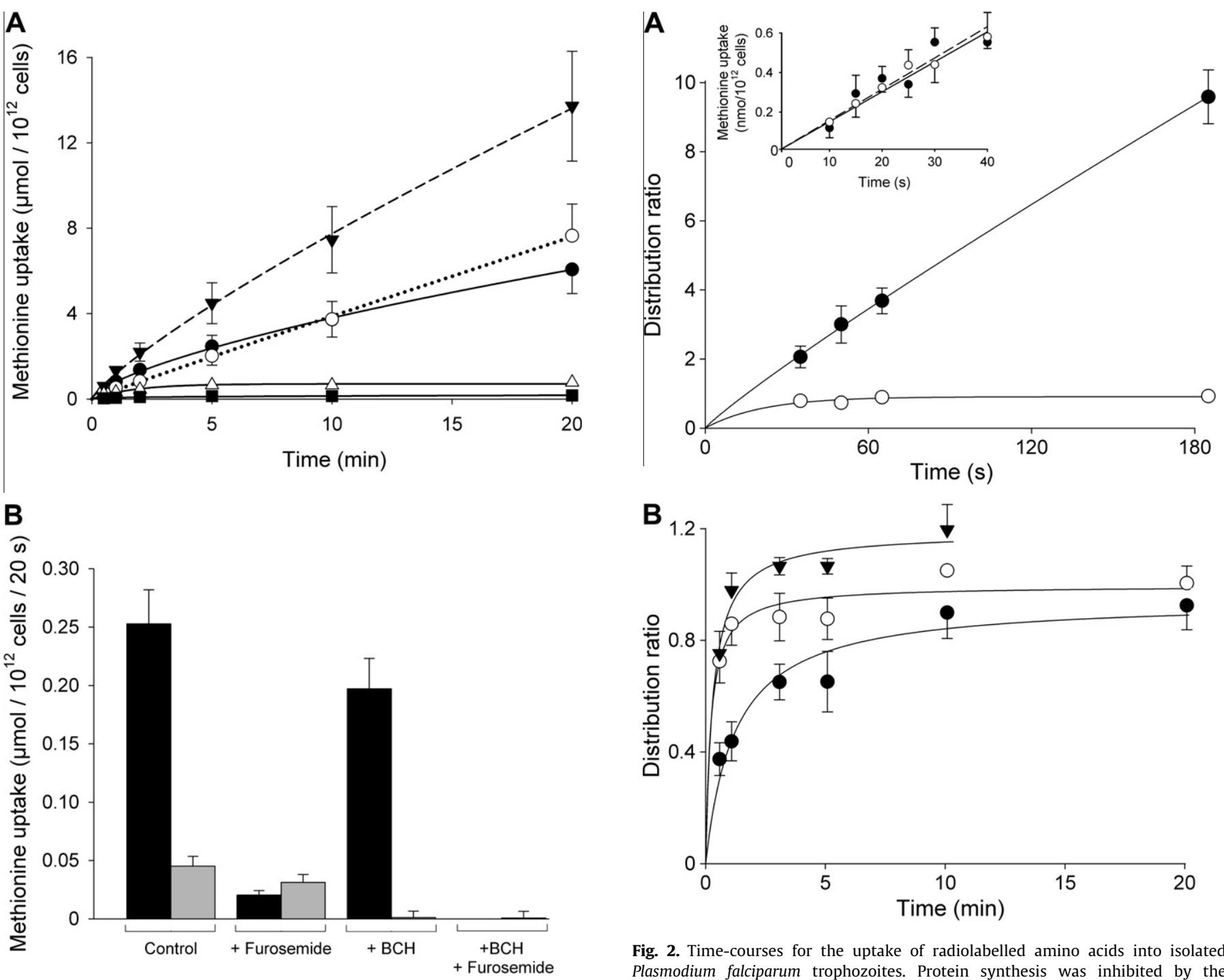

Fig. 1. Uptake of methionine by Plasmodium falciparum-infected and uninfected human erythrocytes at $37^{\circ} \mathrm{C}$. The extracellular medium contained all of the common, naturally-occurring amino acids at concentrations that fall within the normal plasma range. Uninfected cells were from the same donors as the erythrocytes used for parasite culture and were maintained in culture for $48 \mathrm{~h}$ prior to experimentation. (A) Time-courses for the uptake of methionine by $P$. falciparum-infected erythrocytes (in solution A). The symbol $\bullet$ denotes the acidsoluble fraction; $\bigcirc$ denotes the acid-insoluble fraction, and $\boldsymbol{\nabla}$ denotes the combined acid-soluble and acid-insoluble fractions. The graph also shows the uptake (acidsoluble fraction) into ATP-depleted parasitised erythrocytes (suspended in solution $\mathrm{B} ; \triangle$ ) and into uninfected erythrocytes $(\boldsymbol{\square})$. The data are averaged from three separate experiments performed on different days, each on cells from different donors and are shown \pm standard error. Where not shown, error bars fall within the symbols. (B) Effect of inhibitors on methionine influx in P. falciparum-infected cells (black bars) and uninfected cells (grey bars). Methionine influx was determined from the uptake of $\left[{ }^{3} \mathrm{H}\right]$ methionine measured over $20 \mathrm{~s}$ in cells suspended in the presence of the protein synthesis inhibitors cycloheximide $(40 \mu \mathrm{M})$ and anisomycin $(150 \mu \mathrm{M})$, under glucose depleted conditions (solution $\mathrm{B}$ ). Where indicated, furosemide (an inhibitor of the parasite-induced New Permeability Pathways (NPPs)) was added at a concentration of $200 \mu \mathrm{M}$, and aminobicyclo[2.2.1]heptane2-carboxylic acid ( $\mathrm{BCH}$ ) (an inhibitor of the endogenous erythrocyte L-system) was added at a concentration of $20 \mathrm{mM}$. The data are averaged from three separate experiments performed on different days, each on cells from different donors and are shown \pm standard error.

$\left(10^{12}\right.$ cells $\left.\min \right)(n=3 ; \pm$ SE; Fig. $1 \mathrm{~A}$, closed triangles). At the end of the $20 \mathrm{~min}$ time-course approximately half of the radiolabelled methionine taken up into parasitised erythrocytes was incorporated into protein (i.e. the acid-insoluble fraction; open circles) and half remained acid-soluble (closed circles). The initial rate of

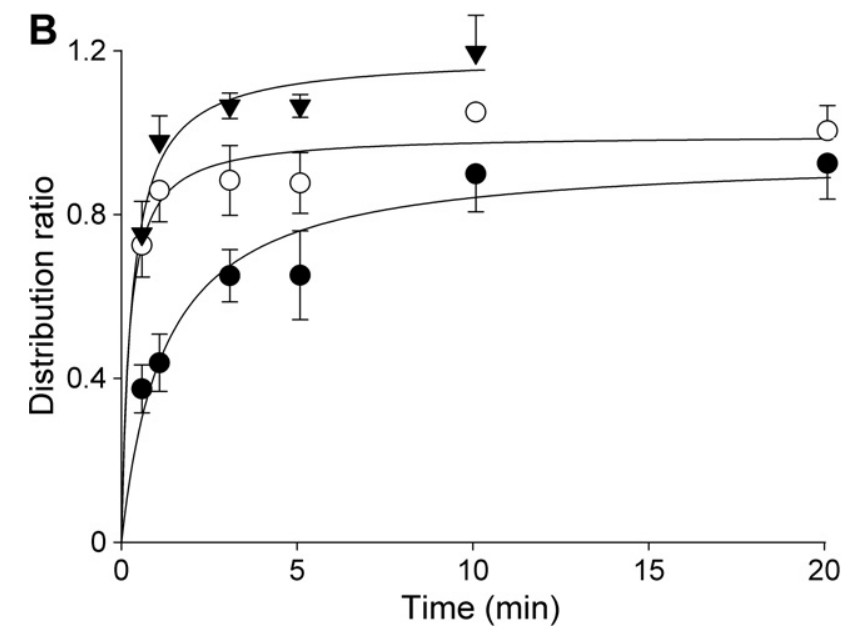

Fig. 2. Time-courses for the uptake of radiolabelled amino acids into isolated Plasmodium falciparum trophozoites. Protein synthesis was inhibited by the addition of cycloheximide $(40 \mu \mathrm{M})$ and anisomycin $(150 \mu \mathrm{M})$. (A) Uptake of $\left[{ }^{3} \mathrm{H}\right]$ methionine into ATP-replete $(\bullet)$ or ATP-depleted $(O)$ parasites pre-incubated (at $37^{\circ} \mathrm{C}$ ) then suspended (at $22^{\circ} \mathrm{C}$ ) in glucose-containing saline (solution $\mathrm{C}$ ) or glucose-free saline (solution $\mathrm{D}$ ), respectively. The extracellular concentration of methionine was $70 \mathrm{nM}$. The inset shows the initial phase of time-courses for the uptake of methionine into ATP-replete (๑, unbroken line) or ATP-depleted $(\bigcirc$, dashed line) parasites pre-incubated (at $37^{\circ} \mathrm{C}$ ) then suspended (at $4{ }^{\circ} \mathrm{C}$ ) in glucosecontaining saline (solution $\mathrm{C}$ ) or glucose-free saline (solution $\mathrm{D}$ ), respectively. Symbols show data averaged from three separate experiments, \pm standard error. (B) Uptake of $\left[{ }^{3} \mathrm{H}\right]$ methionine into parasites suspended in glucose-free saline at either $22{ }^{\circ} \mathrm{C}(\mathrm{O})$ or $4{ }^{\circ} \mathrm{C}(\mathbf{O})$, and of $\left[{ }^{14} \mathrm{C}\right]$ isoleucine into parasites suspended in glucose-free saline at $4{ }^{\circ} \mathrm{C}(\boldsymbol{\nabla})$. The extracellular concentrations of methionine and isoleucine were $70 \mathrm{nM}$ and $2.7 \mu \mathrm{M}$, respectively. The distribution ratio is the concentration of (acid-soluble) radiolabel within the parasite relative to that in the extracellular medium. The data are averaged from four separate experiments performed on different days and are shown \pm standard error.

incorporation of exogenous methionine into protein was $380 \pm 80 \mathrm{nmol} /\left(10^{12}\right.$ cells $\left.\mathrm{min}\right)(n=3 ; \pm \mathrm{SE})$. ATP depletion of the parasitised erythrocytes by pre-incubation in a glucose-free medium caused a marked reduction in the accumulation of radiolabelled methionine within the infected cells (open triangles).

\subsection{Methionine is transported into intact parasitised erythrocytes via the endogenous L-system and the NPPS}

The transport of methionine by normal erythrocytes is predominantly via the L-system (Rosenberg, 1982; Barker and Ellory, 
1990). Fig. 1B illustrates the effects on the influx of methionine into infected and uninfected erythrocytes of the L-system inhibitor aminobicyclo[2.2.1] heptane-2-carboxylic acid (BCH, $20 \mathrm{mM}$ ) (Christensen, 1979), and furosemide $(200 \mu \mathrm{M})$, an effective inhibitor of the NPPs induced by the parasite in the plasma membrane of infected erythrocytes (Kirk et al., 1994). These measurements were made in the presence of protein synthesis inhibitors.

The addition of $\mathrm{BCH}$ to uninfected erythrocytes reduced the influx of methionine by $>95 \%$, consistent with the L-system being the major route of entry of methionine in these cells. In infected erythrocytes the addition of $\mathrm{BCH}$ caused a modest decrease (the actual magnitude of the decrease was not significantly different from that seen in uninfected cells; $P>0.3$, paired Student's $t$ test). However the majority of the influx was insensitive to this inhibitor. By contrast, the NPP inhibitor furosemide reduced the influx of methionine into infected erythrocytes by approximately $90 \%$, while having no significant effect $(P>0.05$; paired Student's $t$ test) on the influx of methionine into uninfected cells. The influx of methionine into infected cells in the presence of furosemide was not significantly different from that into uninfected cells in the presence of furosemide $(P>0.2$, paired Student's paired $t$ test).

The addition of both $\mathrm{BCH}$ and furosemide (together) resulted in complete inhibition of the uptake of methionine into infected cells.

\subsection{Uptake of methionine by isolated P. falciparum trophozoites}

The transport of methionine across the parasite plasma membrane was measured in P. falciparum trophozoites functionally isolated from their host cells by saponin-permeabilisation of the erythrocyte and parasitophorous vacuole membranes, and treated with protein synthesis inhibitors. Fig. 2A shows time-courses for the uptake of radiolabelled methionine into isolated parasites suspended at $22{ }^{\circ} \mathrm{C}$ in a HEPES-buffered saline (solution C) containing $70 \mathrm{nM}$ methionine. In ATP-replete parasites (closed circles) the intracellular (acid-soluble) radiolabel increased steadily throughout the period of the time-course, reaching a distribution ratio of approximately 10 after $3 \mathrm{~min}$. By contrast, in ATP-depleted parasites (suspended in solution D; open circles), the radiolabel equilibrated to a distribution ratio of approximately one within the first $30 \mathrm{~s}$ and remained at this level thereafter.

The nature of the accumulation of radiolabel to distribution ratios well above one in ATP replete (but not ATP-depleted) parasites was not investigated, but may well be due to the metabolism of $\left[{ }^{3} \mathrm{H}\right]$ methionine and the consequent trapping of radiolabel (in acid-soluble forms) within the parasite (see Kirk et al., 2009). To assess whether ATP depletion affected the initial influx of $\left[{ }^{3} \mathrm{H}\right]$ methionine across the parasite plasma membrane, time-courses for the uptake of $\left[{ }^{3} \mathrm{H}\right]$ methionine into ATP-replete and ATP-depleted cells were measured using an alternative technique that entailed reducing the temperature to $4{ }^{\circ} \mathrm{C}$ in order to slow the uptake of radiolabel, and taking samples over the first $20 \mathrm{~s}$ to allow accurate quantitative estimates of the initial rates to be made. As shown in the inset to Fig. 2A, ATP depletion had no significant effect on the influx of $\left[{ }^{3} \mathrm{H}\right]$ methionine into the isolated parasites; the rate of uptake in ATP-replete parasites and ATP-depleted parasites, in paired experiments, was $0.92 \pm 0.15$ and $0.94 \pm 0.10 \mathrm{nmol} /\left(10^{12}\right.$ cells $\left.\mathrm{h}\right)(n=3$; \pm SE; $P>0.05$ paired Student's $t$ test), respectively.

In order to eliminate complications arising from metabolism, all subsequent experiments were carried out in ATP-depleted parasites.

The dependence of the rate of equilibration of radiolabelled methionine in isolated ATP-depleted parasites on temperature is illustrated in more detail in Fig. 2B. On reduction of the temperature from $22{ }^{\circ} \mathrm{C}$ (open circles) to $4{ }^{\circ} \mathrm{C}$ (closed circles) the rate of influx decreased significantly, with uptake at $30 \mathrm{~s}$ reduced from $1.4 \pm 0.17 \mathrm{nmol} /\left(10^{12}\right.$ cells $)$ at $22{ }^{\circ} \mathrm{C}$ to $0.59 \pm 0.06 \mathrm{nmol} /\left(10^{12}\right.$ cells $)$ at $4{ }^{\circ} \mathrm{C}(P<0.005$; unpaired Student's $t$ test $)(n=5 ; \pm$ SE). The final distribution ratio, measured at $20 \mathrm{~min}$, was unaffected $(1.01 \pm$ 0.06 and $0.93 \pm 0.09$, measured at 22 and $4{ }^{\circ} \mathrm{C}$, respectively; $P>0.05$; unpaired Student's $t$ test).

The influx of radiolabelled methionine was substantially slower than that of radiolabelled isoleucine which, even at $4{ }^{\circ} \mathrm{C}$, equilibrated between the intra- and extracellular solutions within approximately $2 \mathrm{~min}$ (Fig. 2B, closed inverted triangles).

Further characterisation of the equilibrative (ATP-independent) transport of radiolabelled methionine into isolated parasites was carried out at $4{ }^{\circ} \mathrm{C}$ in order to allow a more accurate estimate of initial transport rates. Suspension of ATP-depleted isolated parasites in a $\mathrm{Na}^{+}$-free medium (solution $\mathrm{E}$ ) had no significant effect on methionine influx under these conditions; the uptake over the initial $30 \mathrm{~s}$ in the absence of $\mathrm{Na}^{+}$was $0.53 \pm 0.16 \mathrm{nmol} /\left(10^{12}\right.$ cells $)$, compared with an initial rate of $0.59 \pm 0.06 \mathrm{nmol} /\left(10^{12}\right.$ cells $)$ in paired controls ( $n=4 ; \pm S E ; P>0.05$, paired Student's $t$ test; data not shown). Similarly, altering the extracellular $\mathrm{pH}$ from 7.1 to $7.8,6.2$ or 5.5 (in solution F) had no significant effect on the influx of radiolabelled methionine; the uptake over the initial $30 \mathrm{~s}$ in cells at $\mathrm{pH} 7.8\left(0.58 \pm 0.19 \mathrm{nmol} /\left(10^{12}\right.\right.$ cells $\left.)\right)$ was not significantly different from that in cells at $\mathrm{pH} 5.5\left(0.45 \pm 0.15 \mathrm{nmol} /\left(10^{12}\right.\right.$ cells $\left.)\right)$, $\mathrm{pH} 6.2\left(0.78 \pm 0.05 \mathrm{nmol} /\left(10^{12}\right.\right.$ cells $\left.)\right)$ or $7.1(0.59 \pm 0.06 \mathrm{nmol} /$ ( $10^{12}$ cells), $n=4, P>0.4$, one-way ANOVA; data not shown).

3.4. The uptake of methionine into P. falciparum trophozoites is via a saturable transporter

The kinetics of methionine transport in ATP-depleted parasites was investigated by measuring the uptake of $\left[{ }^{3} \mathrm{H}\right]$ methionine over 3 min at $4{ }^{\circ} \mathrm{C}$, in media having a methionine concentration ranging from $2.5 \mu \mathrm{M}$ to $10 \mathrm{mM}$. The results are shown in Fig. 3. Methionine influx was saturable; the concentration-dependence conformed to Michaelis-Menten kinetics, with a $K_{\mathrm{m}}$ of $1.6 \pm 0.3 \mathrm{mM}$ and a $V_{\max }$ of $540 \pm 30 \mu \mathrm{mol} /\left(10^{12}\right.$ cells h $)(n=5 ; \pm \mathrm{SE})$.

\subsection{Competition by other neutral amino acids}

A number of different amino acids and analogues (each at a concentration of $10 \mathrm{mM}$ ) were tested for their ability to compete with,

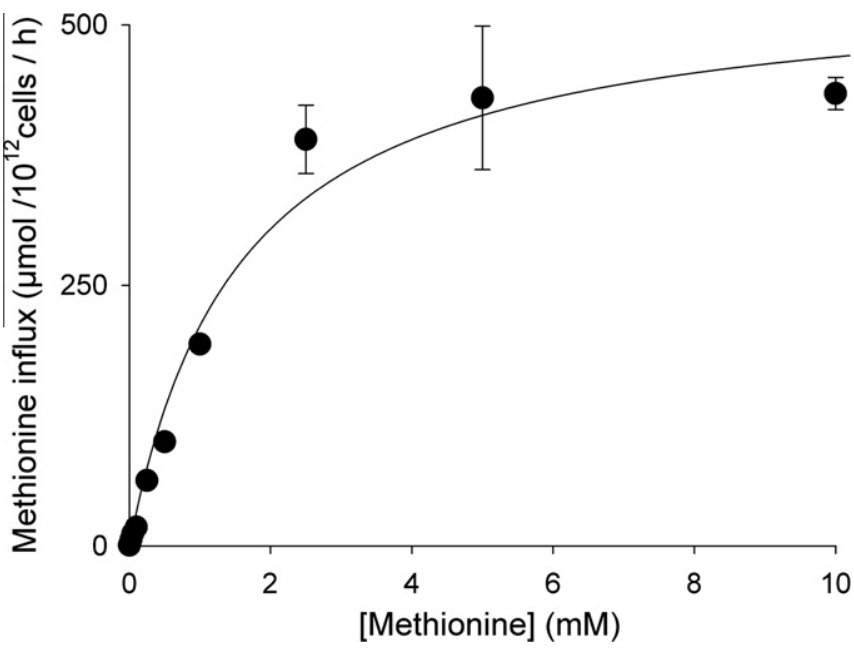

Fig. 3. Concentration-dependence of the initial influx of $\left[{ }^{3} \mathrm{H}\right]$ methionine into isolated ATP-depleted Plasmodium falciparum trophozoites at $4{ }^{\circ} \mathrm{C}$. The uptake of $\left[{ }^{3} \mathrm{H}\right]$ methionine was measured over $3 \mathrm{~min}$, with the concentration of unlabelled methionine ranging from $2.5 \mu \mathrm{M}$ to $10 \mathrm{mM}$. Protein synthesis was inhibited by the addition of cycloheximide $(40 \mu \mathrm{M})$ and anisomycin $(150 \mu \mathrm{M})$. Symbols show data averaged from five separate experiments, \pm standard error, and the curve was drawn using the equation: methionine influx $=V_{\max }$ [met] $/\left(K_{\mathrm{m}}+\right.$ [met] $)$, with $K_{\mathrm{m}}=1.6 \pm$ $0.3 \mathrm{mM}$ and $V_{\max }=540 \pm 30 \mu \mathrm{mol} /\left(10^{12}\right.$ cells h $)$. 

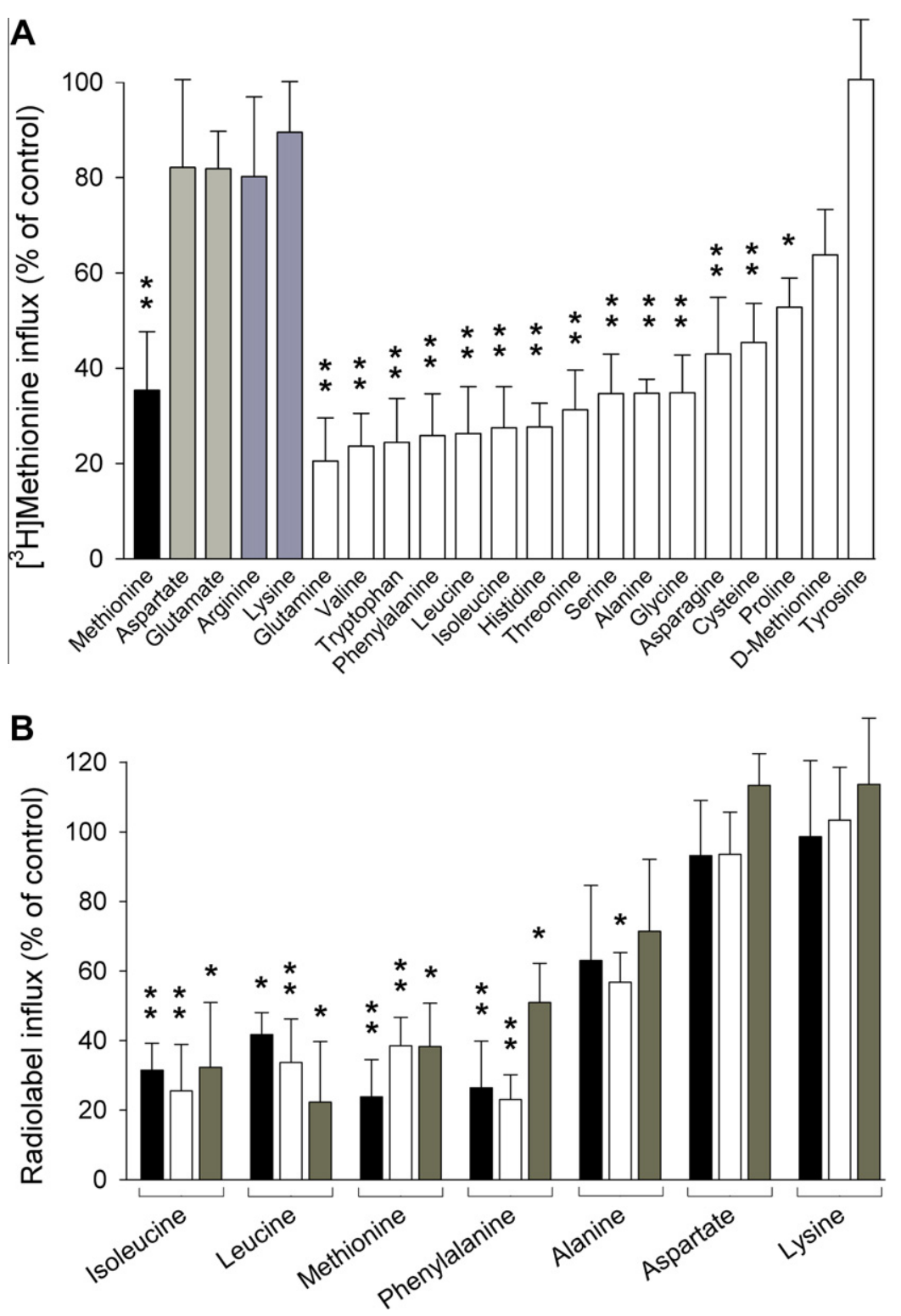

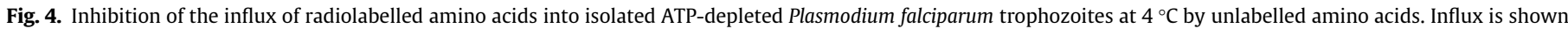

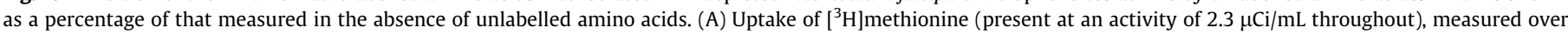

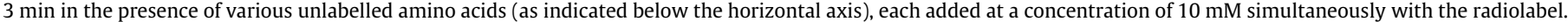

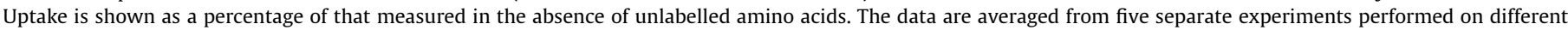

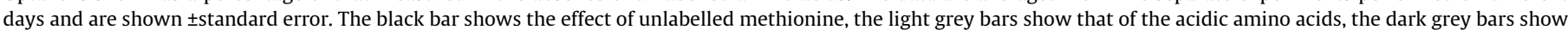

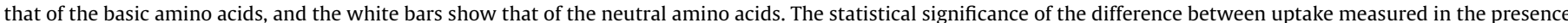

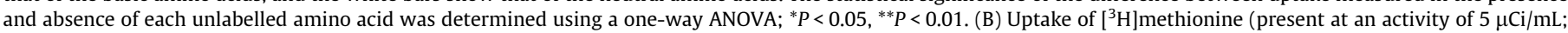

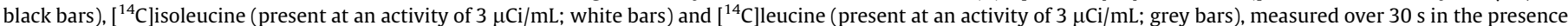

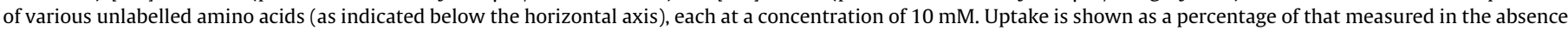

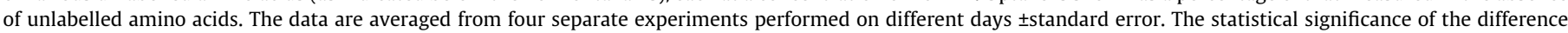

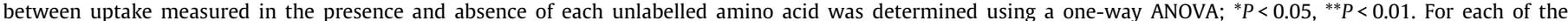

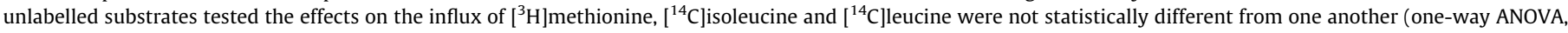
$P>0.05$ ).

and thereby inhibit, the uptake of $\left[{ }^{3} \mathrm{H}\right]$ methionine into ATP-depleted parasites (measured over $3 \mathrm{~min}$ at $4{ }^{\circ} \mathrm{C}$ ). As illustrated in Fig. 4A the acidic amino acids, glutamate and aspartate, and the basic amino acids, arginine and lysine, had no significant effect on the uptake of $\left[{ }^{3} \mathrm{H}\right]$ methionine (all $P>0.05$; one-way ANOVA). The neutral amino acid tyrosine also had no significant effect $(P>0.05)$. However, a wide range of other neutral amino acids caused significant inhibition of $\left[{ }^{3} \mathrm{H}\right]$ methionine uptake (Fig. 4A).

The inhibition of $\left[{ }^{3} \mathrm{H}\right]$ methionine uptake by other neutral amino acids is consistent with these compounds competing with methio- nine for one or more transporters in the parasite membrane. Evidence has previously been presented for the transport of isoleucine and leucine via a saturable transporter in the parasite plasma membrane (Martin and Kirk, 2007). We therefore compared the effects of a selection of the amino acids represented in Fig. $4 \mathrm{~A}$ (each at $10 \mathrm{mM}$ ) on the uptake of $\left[{ }^{3} \mathrm{H}\right]$ methionine, $\left[{ }^{14} \mathrm{C}\right]$ isoleucine and $\left[{ }^{14} \mathrm{C}\right]$ leucine into isolated ATP-depleted parasites (Fig. 4B). For each of the amino acids tested, the effects on the influx of radiolabelled methionine, isoleucine and leucine were not significantly different from one another $(P>0.05$, one-way 


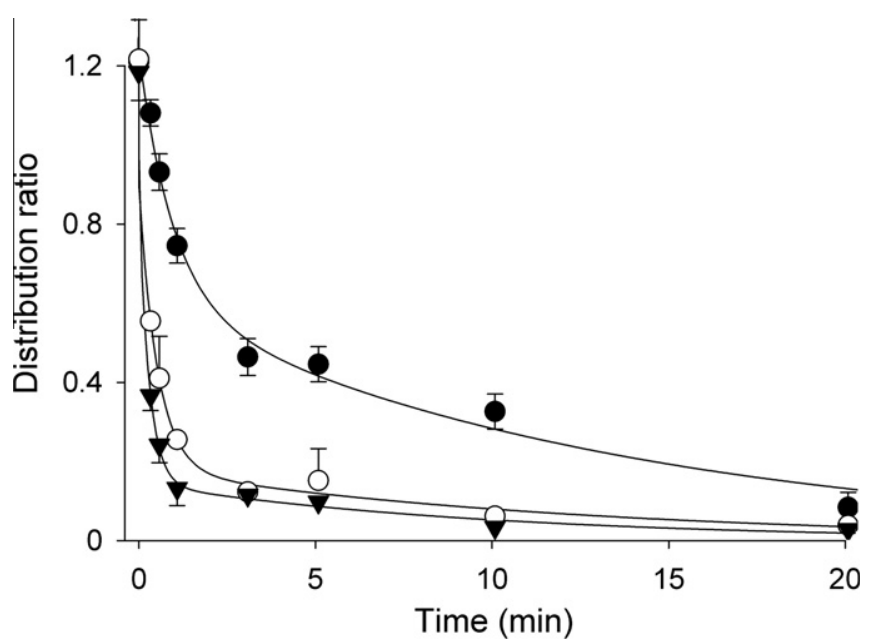

Fig. 5. Time-courses for the efflux of $\left[{ }^{3} \mathrm{H}\right]$ methionine, $\left[{ }^{14} \mathrm{C}\right]$ isoleucine and $\left[{ }^{14} \mathrm{C}\right]$ leucine from isolated ATP-depleted Plasmodium falciparum trophozoites at $4{ }^{\circ} \mathrm{C}$. Isolated parasites were pre-loaded with $\left[{ }^{3} \mathrm{H}\right]$ methionine $(\bullet),\left[{ }^{14} \mathrm{C}\right]$ isoleucine $(\mathrm{O})$ or $\left[{ }^{14} \mathrm{C}\right.$ leucine $(\boldsymbol{\nabla})$ for $10 \mathrm{~min}$ at $37^{\circ} \mathrm{C}$ in the presence of the protein synthesis inhibitors cycloheximide $(40 \mu \mathrm{M})$ and anisomycin $(150 \mu \mathrm{M})$. The cell suspension was cooled to $4{ }^{\circ} \mathrm{C}$ then centrifuged, the extracellular radiolabel was removed, and the cells were resuspended at time-zero in solution $\mathrm{D}$. The data are averaged from three separate experiments performed on different days and are shown \pm standard error. Where not shown, error bars fall within the symbols.

ANOVA). Isoleucine, leucine, methionine and phenylalanine inhibited the uptake of all three radiolabelled amino acids between 49$78 \%$ (all $P<0.05$, one-way ANOVA). Alanine inhibited the uptake of all three by approximately $40 \%$ (N.B. This decrease was statistically significant for $\left[{ }^{14} \mathrm{C}\right]$ isoleucine $(P<0.05$, one-way ANOVA) but not for $\left[{ }^{3} \mathrm{H}\right]$ methionine or $\left[{ }^{14} \mathrm{C}\right]$ leucine). Neither aspartate nor lysine had any significant effect on the uptake of $\left[{ }^{3} \mathrm{H}\right]$ methionine, $\left[{ }^{14} \mathrm{C}\right]$ isoleucine or $\left[{ }^{14} \mathrm{C}\right]$ leucine.

\subsection{Efflux of methionine, isoleucine and leucine from isolated P. falciparum trophozoites}

The majority of amino acids liberated through the digestion of haemoglobin are exported to the extracellular medium (Zarchin et al., 1986; Krugliak et al., 2002). The efflux of amino acids from the parasite therefore plays an important physiological role. Fig. 5 compares time-courses for the efflux of $\left[{ }^{3} \mathrm{H}\right]$ methionine, $\left[{ }^{14} \mathrm{C}\right]$ isoleucine and $\left[{ }^{14} \mathrm{C}\right]$ leucine from ATP-depleted isolated parasites. The efflux of both leucine and isoleucine was rapid; within the first minute approximately $90 \%$ of the pre-loaded leucine and $80 \%$ of the pre-loaded isoleucine had left the cells. Methionine efflux was slower, with approximately $40 \%$ of the pre-loaded methionine exiting the parasites within the first minute.

The estimated half-times for the efflux of leucine, isoleucine and methionine, measured at $4{ }^{\circ} \mathrm{C}$, were $9 \pm 1 \mathrm{~s}, 21 \pm 6 \mathrm{~s}$ and $115 \pm 29 \mathrm{~s}$, respectively ( $n=3 ; \pm \mathrm{SE})$.

\subsection{Trans-stimulation of the influx of methionine and isoleucine into the parasite}

In a previous study of the transport of isoleucine into isolated malaria parasites (Martin and Kirk, 2007) it was shown that the influx of radiolabelled isoleucine was faster under 'exchange' conditions (specifically, when there was unlabelled isoleucine or leucine inside the parasites) than under nominally 'zero-trans' conditions (in which the parasites were depleted of amino acids). This
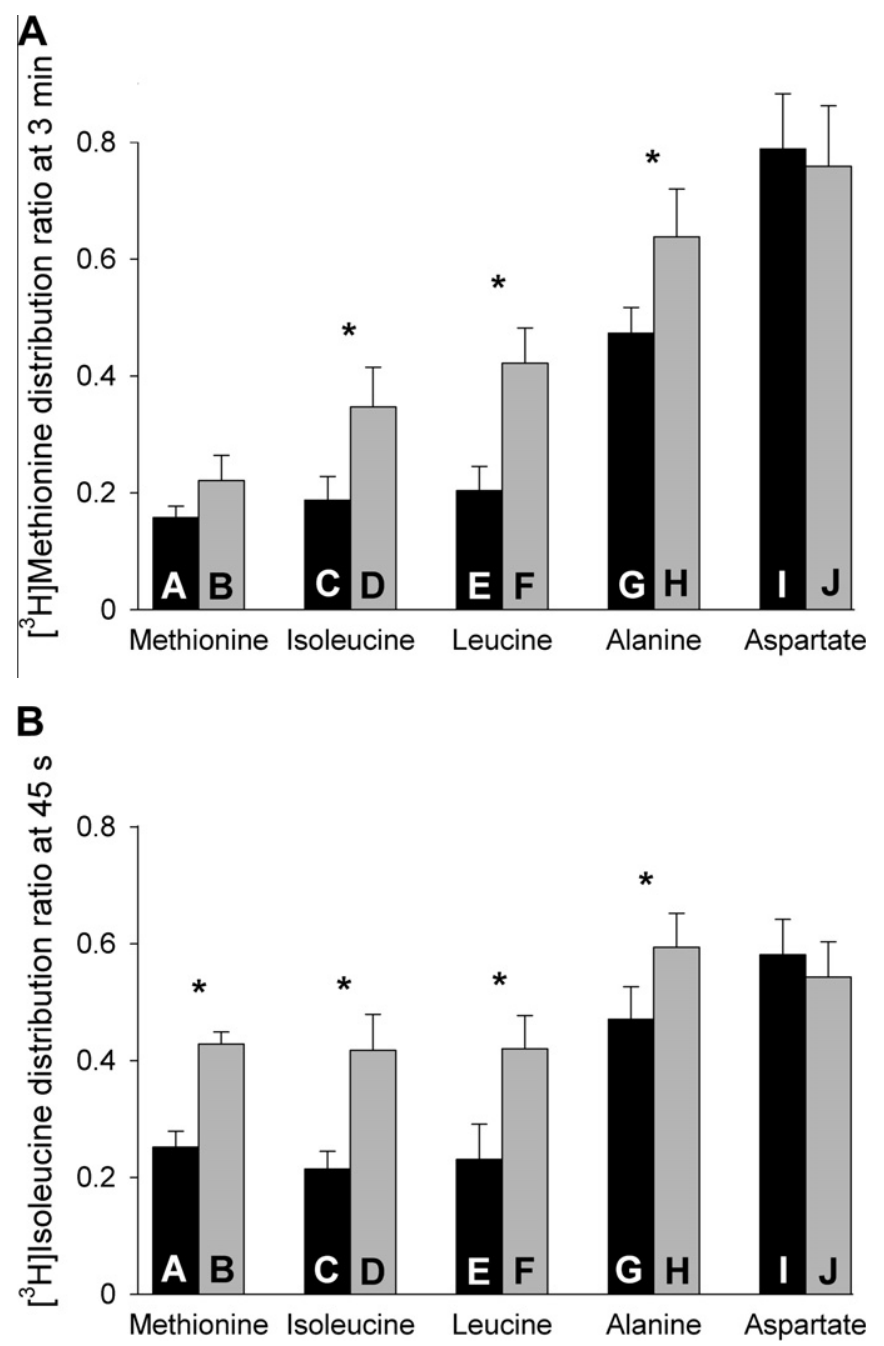

Fig. 6. Trans-stimulation of the influx of $(A)\left[{ }^{3} \mathrm{H}\right]$ methionine and $(B)\left[{ }^{14} \mathrm{C}\right]$ isoleucine into isolated ATP-depleted Plasmodium falciparum trophozoites at $4{ }^{\circ} \mathrm{C}$. (A) Isolated parasites were washed three times in an amino acid-free solution (solution D) and then incubated $\left(10 \mathrm{~min}, 37^{\circ} \mathrm{C}\right.$ ) in either solution $\mathrm{D}$ (for the nominally zero-trans conditions; bars A, C, E, G and I) or solution D supplemented with $1 \mathrm{mM}$ unlabelled methionine, isoleucine, leucine, alanine, or aspartate (for the exchange conditions; bars B, D, F, H and J, respectively). At the end of the incubation the parasites were washed and resuspended in the same solutions supplemented with protein synthesis inhibitors (cycloheximide $(40 \mu \mathrm{M})$ and anisomycin $(150 \mu \mathrm{M}))$. Uptake of $\left[{ }^{3} \mathrm{H}\right]$ methionine, measured over $3 \mathrm{~min}$, commenced at time-zero by combining the parasite suspension with a solution containing the radiolabel together with protein synthesis inhibitors and a sufficient concentration of the appropriate unlabelled amino acid to give a final extracellular amino acid concentration of $1 \mathrm{mM}$. The black bars show uptake (expressed in terms of the distribution ratio at $3 \mathrm{~min}$ ) measured under nominally zero-trans conditions in which the unlabelled amino acids were present in the extracellular medium but nominally absent from the parasite cytosol (bars A, C, E, G and I). The grey bars show uptake measured under exchange conditions, in which the parasites were pre-loaded with the unlabelled amino acids and the amino acid was therefore present at similarly high concentrations at both the extracellular (cis) and intracellular (trans) faces of the parasite plasma membrane throughout the uptake period (bars B, D, F, H and J). The data are averaged from seven separate experiments performed on different days and are shown \pm standard error. (B) Uptake of $\left[{ }^{14} \mathrm{C}\right]$ isoleucine was measured using the same protocol, with uptake measured over $45 \mathrm{~s}$ rather than $3 \mathrm{~min}$ (reflecting the faster rate of transport for isoleucine compared with methionine). The black bars show uptake measured under nominally zero-trans conditions and the grey bars show uptake measured under exchange conditions. The data are averaged from four separate experiments performed on different days and are shown \pm standard error. In both panels $*$ denotes the statistical significance of the difference between the uptake measured under zero-trans and exchange conditions for each of the different (unlabelled) amino acids tested $(P<0.05$; paired Student's $t$ test) 

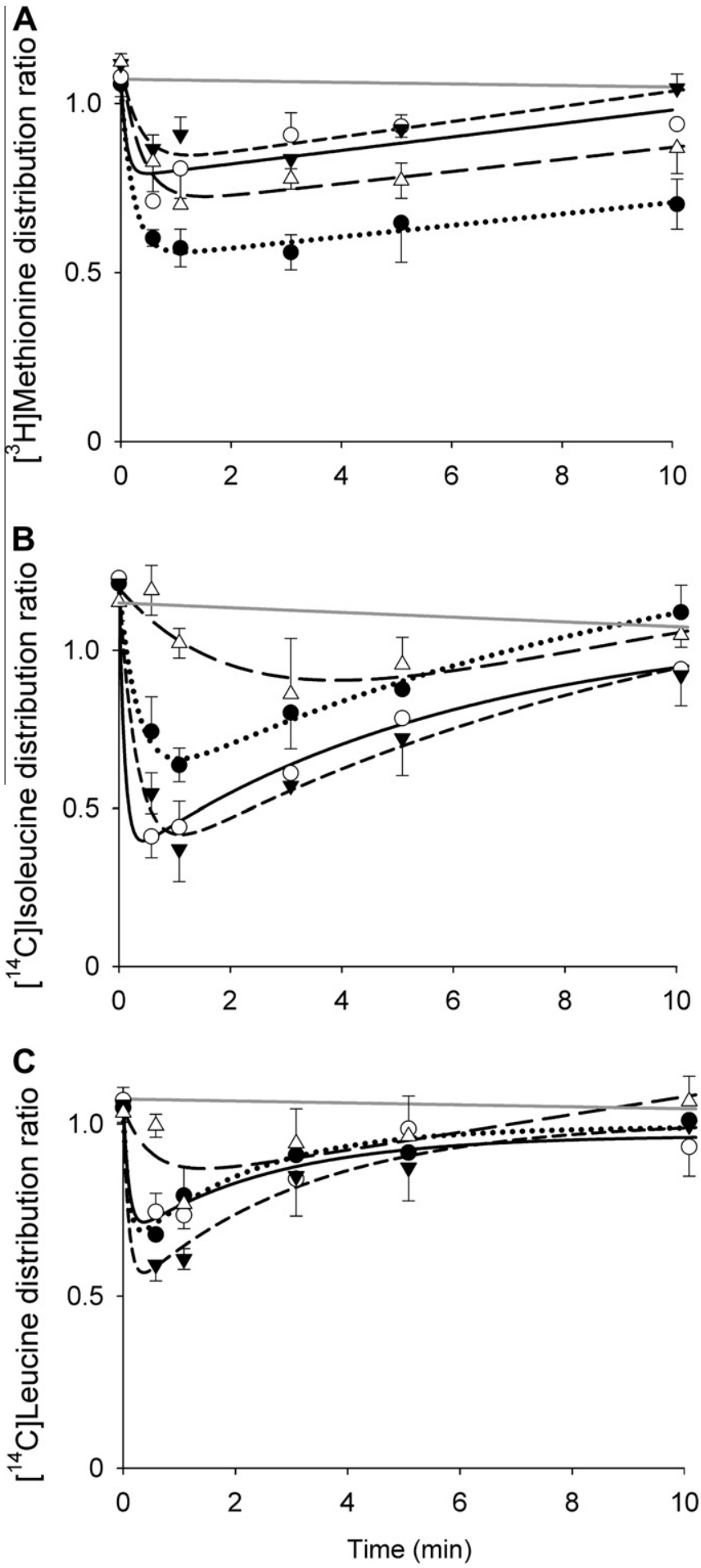

Fig. 7. Trans-stimulation of the efflux of $(A)\left[{ }^{3} \mathrm{H}\right]$ methionine, $(B)\left[{ }^{14} \mathrm{C}\right]$ isoleucine and (C) $\left[{ }^{14} \mathrm{C}\right]$ leucine from isolated Plasmodium falciparum trophozoites at $4{ }^{\circ} \mathrm{C}$. Radiolabelled amino acids were added to ATP-depleted isolated parasites suspended in solution $\mathrm{D}(3.2 \mathrm{~mL})$, in the presence of protein synthesis inhibitors, and allowed to equilibrate before the addition, at time-zero, of a $32 \mu \mathrm{L}$ aliquot of solution $\mathrm{D}$ containing $100 \mathrm{mM}$ methionine ( $\bullet$, dotted line), isoleucine $(\bigcirc$, unbroken line), leucine $(\boldsymbol{\nabla}$, short dashed line), alanine $(\triangle$, long dashed line) or aspartate (grey unbroken line; data points omitted for clarity), giving a final extracellular concentration of $1 \mathrm{mM}$ for the unlabelled amino acid. In control experiments in which the equivalent volume of solution $\mathrm{D}$ alone was added to the cells there was no effect on the intracellular concentration of $\left[{ }^{3} \mathrm{H}\right]$ methionine (i.e. the result was similar to that seen following the addition of aspartate; data not shown). The concentration of radiolabel within the parasite is expressed in terms of the distribution ratio. Each graph shows data averaged from four separate experiments performed on different days ( \pm standard error). phenomenon, known as 'trans-stimulation', is a characteristic of many transporters (Stein, 1990).

Fig. 6A shows the influx of $\left[{ }^{3} \mathrm{H}\right]$ methionine measured under conditions in which there was unlabelled amino acid present (at $1 \mathrm{mM}$ ) either in the extracellular solution alone (nominally 'zerotrans conditions'; black bars), or in both the extracellular and intracellular solutions ('exchange conditions'; grey bars). Influx is shown as the $\left[{ }^{3} \mathrm{H}\right]$ methionine distribution ratio measured at $3 \mathrm{~min}$.

For parasites suspended under nominally zero-trans conditions in medium containing $1 \mathrm{mM}$ unlabelled methionine, $\left[{ }^{3} \mathrm{H}\right]$ methionine reached a distribution ratio of less than 0.2 within the 3 min incubation (bar A). Similarly low distribution ratios were obtained under nominally zero-trans conditions in the presence of $1 \mathrm{mM}$ unlabelled isoleucine (bar C) and leucine (bar E). In the presence of either alanine or aspartate the distribution ratio was close to 0.5 (bar G) and 0.8 (bar I), respectively. The extent of inhibition of $\left[{ }^{3} \mathrm{H}\right]$ methionine uptake by the different amino acids under nominally zero-trans conditions is consistent with that seen in Fig. 4, with unlabelled methionine, isoleucine, leucine and (to a lesser extent) alanine competing with $\left[{ }^{3} \mathrm{H}\right]$ methionine for one or more transporters, and the aspartate not doing so to any significant extent.

Pre-loading parasites with unlabelled isoleucine, leucine or alanine caused a significant increase in $\left[{ }^{3} \mathrm{H}\right]$ methionine influx relative to that seen under the corresponding nominally zero-trans conditions $(P<0.05$; Student's $t$ test; Fig. 6A, grey bars). For cells preloaded with methionine there was a small, but not statistically significant $(P>0.15)$, increase in $\left[{ }^{3} \mathrm{H}\right]$ methionine influx relative to that seen under the corresponding nominally zero-trans conditions. In contrast to the increased influx seen in cells pre-loaded with the four neutral amino acids, the uptake of $\left[{ }^{3} \mathrm{H}\right]$ methionine in parasites pre-loaded with aspartate was the same as that measured under zero-trans conditions $(P>0.35)$.

The trans-stimulation of $\left[{ }^{3} \mathrm{H}\right]$ methionine influx by neutral amino acids (but not by the acidic amino acid, aspartate) and the competition data of Fig. 4 are both consistent with the hypothesis that the neutral amino acids share one or more transporters in the parasite. The results presented in Fig. 6B, showing the influx of $\left[{ }^{3} \mathrm{H}\right]$ isoleucine measured under conditions in which there was unlabelled amino acid present either in the extracellular solution alone (nominally zero-trans conditions; black bars), or in both the extracellular and intracellular solutions (exchange conditions; grey bars) provide further support for this hypothesis. Influx is shown as the $\left[{ }^{3} \mathrm{H}\right]$ isoleucine distribution ratio measured at $45 \mathrm{~s}$ (N.B. The transport of $\left[{ }^{3} \mathrm{H}\right]$ isoleucine occurs at a significantly greater rate than the transport of $\left[{ }^{3} \mathrm{H}\right]$ methionine, hence the shorter incubation). Pre-loading parasites with unlabelled methionine, isoleucine, leucine or alanine caused a significant increase in $\left[{ }^{3} \mathrm{H}\right]$ isoleucine influx relative to that seen under the corresponding nominally zero-trans conditions $(P<0.05)$ whereas aspartate had no significant trans-stimulatory effect $(P>0.15)$.

\subsection{Trans-stimulation of the efflux of isoleucine, methionine and leucine from isolated parasites}

Just as neutral amino acids were able to trans-stimulate the influx of $\left[{ }^{3} \mathrm{H}\right]$ methionine and $\left[{ }^{14} \mathrm{C}\right]$ isoleucine (Fig. 6), so too were they able to trans-stimulate the efflux of $\left[{ }^{14} \mathrm{C}\right]$ isoleucine, $\left[{ }^{3} \mathrm{H}\right]$ methionine and $\left[{ }^{14} \mathrm{C}\right]$ leucine from isolated parasites (Fig. 7). In these experiments, the radiolabelled species was allowed to equilibrate between the cytosol of ATP-depleted parasites and the extracellular solution (solution D). At 'time-zero' unlabelled amino acid (1 $\mathrm{mM}$ of isoleucine, methionine, leucine, alanine or aspartate) was added to the extracellular solution and the concentration of radiolabel remaining within the parasite was monitored over the following $10 \mathrm{~min}$. 
Fig. 7A-C shows the time-courses for the $\left[{ }^{3} \mathrm{H}\right]$ methionine, $\left[{ }^{14} \mathrm{C}\right]$ isoleucine and $\left[{ }^{14} \mathrm{C}\right]$ leucine distribution ratios, respectively, measured over the $10 \mathrm{~min}$ following the addition of unlabelled methionine, isoleucine, leucine, alanine or aspartate to the external medium. For all three radiolabelled species, the neutral amino acids induced a significant transient efflux of radiolabel (determined at $1 \mathrm{~min} ; P<0.01$, one-way ANOVA) whereas the acidic amino acid aspartate did not $(P>0.5)$.

\section{Discussion}

Erythrocytes infected with the human malaria parasite, $P$. falciparum, have long been known to have an increased permeability to a diverse range of low molecular weight solutes, including amino acids (Elford et al., 1985; Ginsburg et al., 1985). The increase has been attributed to the induction in the parasitised erythrocyte membrane of NPPs, thought to be either endogenous (and normally quiescent) erythrocyte channels, somehow activated by the parasite (Huber et al., 2005; Merckx et al., 2009) and/or parasite encoded proteins synthesised, exported and inserted into the erythrocyte membrane by the intracellular parasite (Hill and Desai, 2010; reviewed by Staines et al. (2007). In a recent study (Martin and Kirk, 2007) it was shown that human erythrocytes infected with mature $P$. falciparum trophozoites take up the essential amino acid isoleucine significantly faster than normal uninfected erythrocytes, with the increase attributable to the transport of this amino acid via the NPPs. Similar results were obtained here for methionine. As is represented schematically in Fig. 8, methionine, like isoleucine, is transported into normal erythrocytes via the $\mathrm{BCH}-$ inhibitable) L-system. In mature $P$. falciparum-infected erythrocytes transport of methionine via the L-system occurs at a similar rate to that in uninfected cells but there is, in addition, a large flux through the furosemide-sensitive NPPs, giving rise to an approximately 15 -fold increase in the rate of methionine influx when measured in the presence of approximately physiological amino acid concentrations.

On entering the infected erythrocyte, radiolabelled methionine is taken up by the intracellular parasite, where it is incorporated into protein as well as being accumulated in an acid-soluble form in an ATP-dependent manner (Fig. 8). The rate of incorporation into protein $\left(380 \pm 80 \mathrm{nmol} /\left(10^{12}\right.\right.$ cells min $\left.)\right)$ was, under the conditions of the experiment, significantly higher than the rate of influx via the endogenous erythrocyte L-system (as estimated from the $\mathrm{BCH}$-sensitive component of methionine influx in parasitised erythrocytes; $73 \pm 10 \mathrm{nmol} /\left(10^{12}\right.$ cells $\left.\mathrm{min}\right)$, but substantially lower than the overall rate of influx into parasitised erythrocytes $\left(1.10 \pm 0.21 \mu \mathrm{mol} /\left(10^{12}\right.\right.$ cells $\left.\left.\mathrm{min}\right)\right)$. The transport of methionine via the NPPs therefore serves to ensure that the rate of incorporation of exogenous methionine into protein by the parasite is not rate-limited by transport across the erythrocyte membrane.

The ATP-dependent accumulation of radiolabel in an acid-soluble form is likely to represent an energy-dependent accumulation and/or metabolic conversion of the amino acid to a membrane-

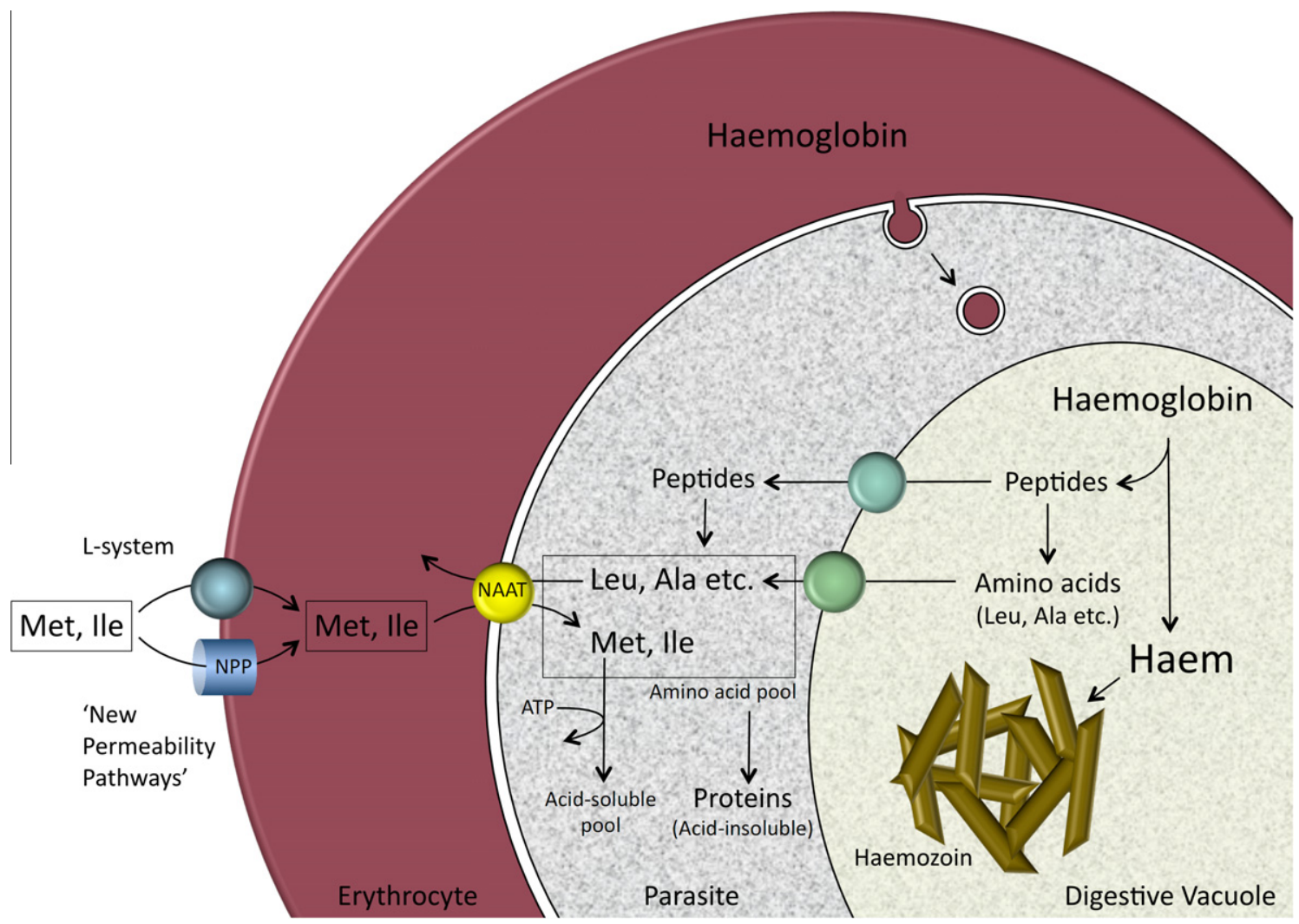

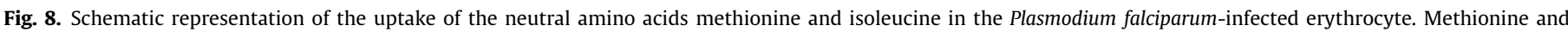

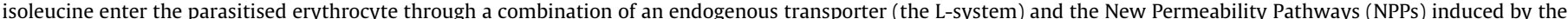

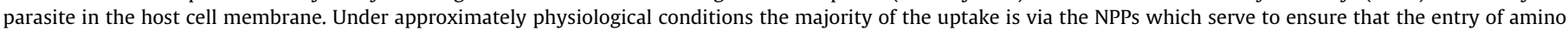

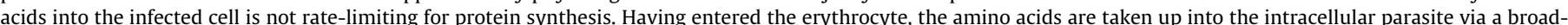

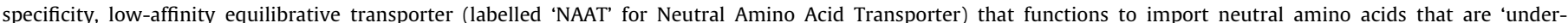

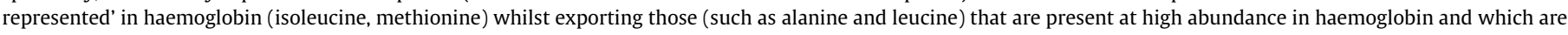

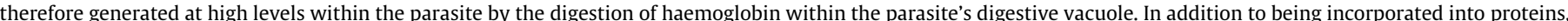

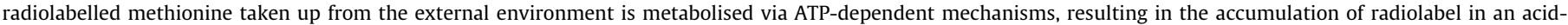
soluble fraction. 
impermeant form within the parasite. This was not investigated further. Instead, the transport of methionine across the parasite plasma membrane was characterised in some detail.

As is illustrated schematically in Fig. 8, the influx of methionine into the parasite is mediated by an ATP-independent transport mechanism (Fig. 2A inset) that serves to equilibrate the intraand extracellular methionine concentrations (i.e. it results in a distribution ratio close to 1 ; Fig. 2A). Transport was shown to be temperature-dependent (Fig. 2B), saturable ( $K_{\mathrm{m}}=1.6 \pm 0.3 \mathrm{mM}$; Fig. 3 ), and independent of $\mathrm{Na}^{+}$or $\mathrm{H}^{+}$. It was competed by a wide range of neutral amino acids, but not to any significant extent by either acidic or basic amino acids (Fig. 4A). The pattern of competition observed for the influx of methionine was very similar to that observed for the influx of both isoleucine and leucine (Fig. 4B), consistent with these three neutral amino acids being substrates for one or more common transporters in the parasite plasma membrane. The observations that: (i) the influx of radiolabelled methionine and isoleucine showed similar patterns of trans-stimulation by pre-loaded neutral amino acids; and (ii) the addition of unlabelled methionine, isoleucine and leucine (as well as alanine), but not aspartate, to the extracellular medium stimulated the efflux of radiolabelled methionine, isoleucine and leucine (Fig. 7), are again consistent with this hypothesis. As is clear from both the influx time-courses of Fig. $2 \mathrm{~B}$ and the efflux time-courses of Fig. 5, the transport of methionine across the parasite plasma membrane was significantly slower than that of isoleucine and leucine, perhaps reflecting a lower affinity of the transporter(s) for methionine compared with isoleucine and leucine. Consistent with this, the $K_{\mathrm{m}}$ for the influx of methionine into isolated parasites was estimated here to be $1.6 \mathrm{mM}$, whereas the $K_{\mathrm{m}}$ for the influx of isoleucine into isolated parasites has been estimated previously to be $\leqslant 0.55 \mathrm{mM}$ (Martin and Kirk, 2007).

In the previous study (Martin and Kirk, 2007) it was found that the addition of unlabelled methionine $(1 \mathrm{mM})$ did not prevent the equilibration of radiolabelled isoleucine across the parasite plasma membrane, as measured over $15 \mathrm{~s}$ at $20^{\circ} \mathrm{C}$, whereas unlabelled isoleucine and leucine (each at a concentration of $1 \mathrm{mM}$ ) did. These data contrast with the finding in the present study that a $10 \mathrm{mM}$ concentration of unlabelled methionine did reduce the uptake of radiolabelled isoleucine (as well as radiolabelled leucine and methionine) measured over $30 \mathrm{~s}$ at $4{ }^{\circ} \mathrm{C}$. This apparent discrepancy may be accounted for by the fact that at the higher temperature used in the previous study isoleucine equilibrated within a few seconds (or less); under these conditions, methionine could cause quite a marked inhibition of influx yet still not prevent equilibration occurring over the $15 \mathrm{~s}$ incubation period used. This notwithstanding, the earlier data are again consistent with the hypothesis that the proposed common neutral amino acid transporter(s) has/ have a higher affinity for isoleucine and leucine than for methionine.

The data of Figs. 6 and 7 illustrate the fact that the unidirectional transport of one neutral amino acid, either into or out of the parasite, is trans-stimulated by the movement of another neutral amino acid in the opposite direction. As has been noted previously in relation to the uptake of the essential amino acid isoleucine (Martin and Kirk, 2007), this property of the putative transporter - i.e. operating with maximum efficiency when exchanging one neutral amino acid for another, a consequence of the substrate-loaded transporter undergoing the necessary conformational change more rapidly than the empty transporter - provides the parasite with a mechanism for taking up neutral amino acids that are under-represented in adult human haemoglobin (and which the parasite therefore requires from the external medium; e.g. isoleucine and methionine) in exchange for neutral amino acids that are over-represented (leucine and alanine make up 25\% of the residues in adult human haemoglobin (Kolakovich et al.,
1997)) and which the parasite has to release in order to avoid osmotic overload.

The failure of anionic or cationic amino acids either to impede, or to trans-stimulate, the transport of radiolabelled neutral amino acids indicate that if these charged amino acids are substrates of the neutral amino acid transporter(s) described here they have a much lower affinity for the system(s) than do the neutral amino acids.

The molecular identity of the transporter(s) facilitating the transport of amino acids across the parasite plasma membrane is yet to be established. The $P$. falciparum genome is known to encode at least six candidate amino acid transporters (Martin et al., 2005, 2009) and all are expressed in blood stage parasites (Bozdech et al., 2003; Le Roch et al., 2003; Llinas et al., 2006). The substrate specificity and subcellular localisation of these proteins are yet to be established.

Whatever their identity, the transporter protein(s) involved in the flux of amino acids across the parasite plasma membrane may well be suitable drug targets, either in their own right or in combination with the pathways involved in haemoglobin degradation. Inhibition of amino acid influx has the potential to starve the parasite of essential nutrients. Inhibition of the efflux of amino acids liberated by haemoglobin degradation will result in a potentially lethal osmotic imbalance within the parasite.

\section{Acknowledgements}

This work was supported by the Australian National Health and Medical Research Council (Project Grant No. 525428). We are grateful to the Canberra branch of the Australian Red Cross Blood Service for the provision of blood.

\section{References}

Allen, R.J., Kirk, K., 2004. The membrane potential of the intraerythrocytic malaria parasite Plasmodium falciparum. J. Biol. Chem. 279, 11264-11272.

Allen, R.J., Kirk, K., 2009. Plasmodium falciparum culture: the benefits of shaking. Mol. Biochem. Parasitol. 169, 63-65.

Alleva, L.M., Kirk, K., 2001. Calcium regulation in the intraerythrocytic malaria parasite Plasmodium falciparum. Mol. Biochem. Parasitol. 117, 121-128.

Barker, G.A., Ellory, J.C., 1990. The identification of neutral amino acid transport systems. Exp. Physiol. 75, 3-26.

Bozdech, Z., Llinas, M., Pulliam, B.L., Wong, E.D., Zhu, J., DeRisi, J.L., 2003. The transcriptome of the intraerythrocytic developmental cycle of Plasmodium falciparum. PLoS Biol. 1, E5.

Christensen, H.N., 1979. Exploiting amino acid structure to learn about membrane transport. Adv. Enzymol. Relat. Areas Mol. Biol. 49, 41-101.

Divo, A.A., Geary, T.G., Davis, N.L., Jensen, J.B., 1985. Nutritional requirements of Plasmodium falciparum in culture. I. Exogenously supplied dialyzable components necessary for continuous growth. J. Protozool. 32, 59-64.

Elford, B.C., Haynes, J.D., Chulay, J.D., Wilson, R.J., 1985. Selective stage-specific changes in the permeability to small hydrophilic solutes of human erythrocytes infected with Plasmodium falciparum. Mol. Biochem. Parasitol. 16, 43-60.

Ginsburg, H., Kutner, S., Krugliak, M., Cabantchik, Z.I., 1985. Characterization of permeation pathways appearing in the host membrane of Plasmodium falciparum infected red blood cells. Mol. Biochem. Parasitol. 14, 313-322.

Hill, D.A., Desai, S.A., 2010. Malaria parasite mutants with altered erythrocyte permeability: a new drug resistance mechanism and important molecular tool. Future Microbiol. 5, 81-97.

Huber, S.M., Duranton, C., Lang, F., 2005. Patch-clamp analysis of the "new permeability pathways" in malaria-infected erythrocytes. Int. Rev. Cytol. 246 59-134.

Kirk, K., Horner, H.A., Elford, B.C., Ellory, J.C., Newbold, C.I., 1994. Transport of diverse substrates into malaria-infected erythrocytes via a pathway showing functional characteristics of a chloride channel. J. Biol. Chem. 269, 3339-3347.

Kirk, K., Howitt, S.M., Broer, S., Saliba, K.J., Downie, M.J., 2009. Purine uptake in Plasmodium: transport versus metabolism. Trends Parasitol. 25, 246-249.

Kolakovich, K.A., Gluzman, I.Y., Duffin, K.L., Goldberg, D.E., 1997. Generation of hemoglobin peptides in the acidic digestive vacuole of Plasmodium falciparum implicates peptide transport in amino acid production. Mol. Biochem. Parasitol. 87, 123-135.

Krugliak, M., Zhang, J., Ginsburg, H., 2002. Intraerythrocytic Plasmodium falciparum utilizes only a fraction of the amino acids derived from the digestion of host cell cytosol for the biosynthesis of its proteins. Mol. Biochem. Parasitol. 119, 249256. 
Lambros, C., Vanderberg, J.P., 1979. Synchronization of Plasmodium falciparum erythrocytic stages in culture. J. Parasitol. 65, 418-420.

Le Roch, K.G., Zhou, Y., Blair, P.L., Grainger, M., Moch, J.K., Haynes, J.D., De La Vega, P. Holder, A.A., Batalov, S., Carucci, D.J., Winzeler, E.A., 2003. Discovery of gene function by expression profiling of the malaria parasite life cycle. Science 301, 1503-1508.

Liu, J., Istvan, E.S., Gluzman, I.Y., Gross, J., Goldberg, D.E., 2006. Plasmodium falciparum ensures its amino acid supply with multiple acquisition pathways and redundant proteolytic enzyme systems. Proc. Natl. Acad. Sci. USA 103, $8840-8845$.

Llinas, M., Bozdech, Z., Wong, E.D., Adai, A.T., DeRisi, J.L., 2006. Comparative whole genome transcriptome analysis of three Plasmodium falciparum strains. Nucleic Acids Res. 34, 1166-1173.

Loria, P., Miller, S., Foley, M., Tilley, L., 1999. Inhibition of the peroxidative degradation of haem as the basis of action of chloroquine and other quinoline antimalarials. Biochem. J. 339, 363-370.

Martin, R.E., Ginsburg, H., Kirk, K., 2009. Membrane transport proteins of the malaria parasite. Mol. Microbiol. 74, 519-528.

Martin, R.E., Henry, R.I., Abbey, J.L., Clements, J.D., Kirk, K., 2005. The 'permeome' of the malaria parasite: an overview of the membrane transport proteins of Plasmodium falciparum. Genome Biol. 6, R26.

Martin, R.E., Kirk, K., 2007. Transport of the essential nutrient isoleucine in human erythrocytes infected with the malaria parasite Plasmodium falciparum. Blood $109,2217-2224$

McCormick, G.J., 1970. Amino acid transport and incorporation in red blood cells of normal and Plasmodium knowlesi-infected rhesus monkeys. Exp. Parasitol. 27. 143-149.

Merck, 1974. Clinical Laboratory: Medico-Chemical Investigation Methods. (11th) Merck \& Co., Inc., Darmstadt, Germany. pp. 525-526.

Merckx, A., Bouyer, G., Thomas, S.L., Langsley, G., Egee, S., 2009. Anion channels in Plasmodium-falciparum-infected erythrocytes and protein kinase A. Trends Parasitol. 25, 139-144.

Rosenberg, R., 1982. Na-independent and Na-dependent transport of neutral amino acids in the human red blood cell. Acta Physiol. Scand. 116, 321-330.
Saliba, K.J., Horner, H.A., Kirk, K., 1998. Transport and metabolism of the essential vitamin pantothenic acid in human erythrocytes infected with the malaria parasite Plasmodium falciparum. J. Biol. Chem. 273, 10190-10195.

Saliba, K.J., Kirk, K., 1999. pH regulation in the intracellular malaria parasite, Plasmodium falciparum. $\mathrm{H}^{+}$extrusion via a V-type $\mathrm{H}^{+}$-ATPase. J. Biol. Chem. 274, 33213-33219.

Sherman, I.W., 1977. Transport of amino acids and nucleic acid precursors in malarial parasites. Bull. World Health Organ. 55, 211-225.

Sherman, I.W., Tanigoshi, L., Mudd, J.B., 1971. Incorporation of ${ }^{14} \mathrm{C}$-amino acids by malaria (Plasmodium lophurae): II. Migration and incorporation of amino acids. Int. J. Biochem. 2, 27-40.

Siddiqui, W.A., Schnell, J.V., 1972. In-vitro and in-vivo studies with Plasmodium falciparum and Plasmodium knowlesi. Proc. Helm. Soc. Wash. 39, 204-210.

Spillman, N.J., Allen, R.J., Kirk, K., 2008. Acid extrusion from the intraerythrocytic malaria parasite is not via a $\mathrm{Na}^{+} / \mathrm{H}^{+}$exchanger. Mol. Biochem. Parasitol. 162, 9699.

Staines, H.M., Alkhalil, A., Allen, R.J., De Jonge, H.R., Derbyshire, E., Egee, S., Ginsburg, H., Hill, D.A., Huber, S.M., Kirk, K., Lang, F., Lisk, G., Oteng, E., Pillai, A.D., Rayavara, K., Rouhani, S., Saliba, K.J., Shen, C., Solomon, T., Thomas, S.L., Verloo P., Desai, S.A., 2007. Electrophysiological studies of malaria parasite-infected erythrocytes: current status. Int. J. Parasitol. 37, 475-482.

Stein, W.D., 1990. Channels, Carriers, and Pumps: An Introduction to Membrane Transport. Academic Press Inc., London.

Teng, R., Junankar, P.R., Bubb, W.A., Rae, C., Mercier, P., Kirk, K., 2009. Metabolite profiling of the intraerythrocytic malaria parasite Plasmodium falciparum by ${ }^{1} \mathrm{H}$ NMR spectroscopy. NMR Biomed. 22, 292-302.

Tunnicliff, G., 1994. Amino acid transport by human erythrocyte membranes. Comp. Biochem. Physiol. 108, 471-478.

Winter, G.C., Christensen, H.N., 1964. Migration of amino acids across the membrane of the human erythrocyte. J. Biol. Chem. 239, 872-878.

Zarchin, S., Krugliak, M., Ginsburg, H., 1986. Digestion of the host erythrocyte by malaria parasites is the primary target for quinoline-containing antimalarials. Biochem. Pharmacol. 35, 2435-2442. 